\title{
The Link between Participation, Leadership, Social Capital and Personal Psychology with Economic Empowerment among Women Smallholder Groups in Malaysia
}

\author{
Fauziah binti Ani ${ }^{a}$ \\ A \\ Universiti Tun Hussein Onn Malaysia
}

Article History: Received: 11 January 2021; Accepted: 27 February 2021; Published online: 5 April 2021

\begin{abstract}
Many developing countries turn to women groups as a way to empower women of similar socioeconomic backgrounds. In this regard, this research was conducted to study the relationship between the level of participation, leadership, social capital, personal psychology and economic empowerment among members of women smallholder groups. A total of 433 members of women smallholder groups involved in economic development activities were selected from four Peninsular Malaysia states covering four regions: south, east, west, and north. Through utilizing questionnaires, the results of this analysis were obtained and analysed with the Pearson Product Moment Correlation -SPSS. The findings show that these four independent variables are related moderately and highly to economic empowerment. Based on the study findings, it is possible to improve the economic empowerment of women smallholder groups by paying attention to those four variables.
\end{abstract}

Keywords: Economic empowerment, participation, social capital, leadership and personal psychology

\section{Introduction}

Female economic empowerment is a process for women to achieve access and control over their own economic source, and ensure they can be used to improve their control over other aspects of their lives. This goal is the basic global priority based on its potential contributions to the Sustainable Development Goals (SDGs) (Taylor and Pereznieto, 2014).

The United Nations (UN) and most developing countries target women as requiring empowerment via development activities. This group require help to reduce poverty rates in rural areas, and provide opportunities for them to exercise control over their own lives (Moyle, Dollard \& Biswas, 2006). Therefore, the Communitybased Organisations (CBOs) are established as platforms for women to improve their standard of living. Among active CBOs in most countries include micro-credit unions, farmer's associations, youth clubs, women's groups, resident associations, faith-based organisations, parent associations, and so on (Opare,2007; Bess et al., 2011). In Malaysia, among the women groups playing an important role in rural community development are groups such as the Women Smallholders Movement (PWPK) under RISDA, the Dynamic Women's Association (WADIRA) under FELCRA, the Women's Extension Group (KPW) under the Department of Agriculture, the PWPK under the Amanah Ikhtiar Malatysia (AIM), and others.

For Malaysian rural women, their economic activities mainly began as social group activities set up under government programmes. They cooperate and pool ideas while participating in these activities. However, this approach could not continue and develop further into business, due to arising conflicts during the process of undertaking and managing the industry (Maimunah, 2001; Jariah et al., 2003; and Jariah \& Laily, 1995). Therefore, they turn to individual-level business, with family members or a few partners and establish business ready for development and improvement. The skills required to interact with partners, family members, staff, community members, and other related groups are still important for the success of their ventures.

The focus of this study is the PWPK, as this organisation is also one of the CBOs set up for rural development to empower women in smallholder families. The PWPK was set up by RISDA (Rubber Industry Smallholders Development Authority) to empower women, wives and daughters of smallholders in the supplementary economic aspect to help their husbands and families increase their income and improve their standard of living. Since 2018, there are 776 PWPKs with 13,986 members in Malaysia (Table 1). These groups are established in villages that depend on the agricultural sector as their source of income, and consist of 15 women between 13 and 65 years of age, across ethnic, religious, and political lines. As an agency supporting the government goals and plans to empower rural communities, RISDA provides guidance, know-how, skills, and loans to PWPK members to mobilise them towards community well-being activities and economic betterment.

Among these economic-based activities by PWPK members include generating additional economy through entrepreneurship and traditional small businesses, using agriculture-based materials to make handicrafts such as rubber leaves, snacks, food processing, sewing, groceries, furniture, livestock, and so on. The PWPK also initiated various projects such as homestays, handicrafts, groceries, eateries, sewing, farmer's market, vegetable crops, rice, and livestock, according to the members' existing skills and experience. PWPK member incomes are also increased through participatory development approaches, thus improving women empowerment. For example, in 2011 the Johor PWPK earned RM 819,588, the highest income among the states. Members are encouraged to be self-reliant through government financial support. However, despite the various aids provided, some PWPK members are still 
unable to achieve economic empowerment as targeted by RISDA. The income earned barely goes beyond survival. Many among them are also inactive in additional economic activities. The government targets the household income of B40 groups, or the lower 40\% household income groups earning less than RM5000 a month in 2020. According to the latest statistics, there are 2.7 million people categorised in the B40 group, including smallholder households.

Therefore, this study aims to study the link and factors influencing economic empowerment of PWPK members in Malaysia. The factors studied to understand economic empowerment covers two perspectives: sociology and internal psychology. The sociological perspective consists of CBO structure traits, such as leadership, participation, and social capital.

\section{Economic Empowerment}

Economic empowerment is a key aspect in community development. Generally, economic empowerment measures the extent of a community's success in increasing their economic capability. Specifically, economic empowerment means the extent a community is able to improve their economic status through income, savings and assets, as a result of their economic participation. This refers to economic strength, either at the individual or group level believed as the basis of political and social strength. Moyle, Dollard \& Biswas (2006), Mayoux (2000), Saidu \& Asnarulkhadi (2014) define economic empowerment as the ability to earn sufficient income to purchase basic necessities such as housing, food, clothing, children education, and others for a more comfortable way of living. However, this economic capacity according to Moyle, Dollard \& Biswas (2006) \& Mayoux (2000) is obtained though providing freedom in decision-making among community members. From this position, individuals improve their capability of earning income through participation in economic-generating activities.

The economic-generating activities are seen as the most important alternative sector in instilling socioeconomic development and reducing the poverty rate in both developed and developing countries. Through generating this economic activity, savings and wealth and living standards can be improved. In addition. The generating of this additional economic serves to improve the socio-economic conditions of the poor such as better education, health, housing, and diet, making this sector highly preferable.

The main idea behind this economic-generating activity is to help the community earn extra income to transform their economic status towards something better. Empowering the poor in the community via economic activities is the ultimate solution to reducing poverty. The individual can improve their ability to produce income by increasing their access to basic needs, providing comfortable residence, and capable of obtaining better education for their children (Mohammed Bashir Saidu \& Samah, 2014). Studies have revealed that CBO members are capable of increasing their income. The findings are also in line with Chandrashekar and Lokesh (2009), which observed that all members are able to maintain savings. All members achieve economic freedom and are capable of increasing capital formation after joining the CBO (Yadav, R., Sagar, M.P.,Tripathi, H., Kumar, P., Balaraju, B.L., Sinha, S.K., \& Ramesh, N.; 2016). Ethnographic studies (Hashemi, Schuler, \& Riley, 1996) on six villages in rural Bangladesh document the positive effects of female participation in Self-Help Groups that lead to economic empowerment, ability for small and large purchases, and increase in participation in domestic decision-making.

Previous studies such as Ahmed, Chamhuri Siwar \& Noraini Idris (2011), Jakimow (2007), Mok (2005), Moyle, Dollard \& Biswas (2006), Ndaeji \&Asnarulkhadi (2013) show women groups play a role in managing communities and implementing development activities that impact community members' stage of empowerment. Meanwhile, Nur Hafizah Yusof \& Rahimah Abdul Aziz (2012) found that through the Women's Economic Group (KEW), members are capable of generating extra income to improve family standard of living as well as improve self-efficacy through experience and training.

\section{Participation, Leadership, Social Capital and Psychology}

In community development, empowerment shapes intervention-oriented resource approach. In citizenship and democracy education, empowerment is seen as a tool to improve citizen responsibility. Empowerment is also a concept that moves from deficit-oriented to strength-oriented, which can be increased through concepts of management, continuing education, and self-help groups. Economic empowerment can be improved through a combination of factors from both the sociological and psychological perspectives. Participation, leadership, and social capital are important sociological factors at the organisational stage, and psychologically at the individual stage that contributes to economic empowerment.

\subsection{Community Participation}

Community participation has been observed by Abbott (1995), Asnarulkhadi (2006), Asnarulkhadi \& Aref (2011), Hung, Sirakaya-Turk \& Ingaram (2010), and Cummings (1997) from two perspectives: participation as means, and participation as goals. As means, community members are not directly involved in decision-making, it being determined by the government to achieve set objectives and possibly not in line with their wishes (Asnarulkhadi \& Aref, 2011). As goals, participation refers to community member direct involvement in the decision-making, planning, and development-activity implementing processes, according to their needs and wishes. This is also seen as a process to help develop the capacity of community members or the capability of identifying and improving their self-potential. This participation is also seen by Moser (1989) as using the bottomup approach. 
Women participation in informal groups also provide the key opportunity to expand their self-confidence and self-trust, as well as effective leadership skills. This opens the road for women to sharpen their skills by assuming leadership positions in informal or alternative formal structures.

\subsection{Community Leadership}

Community leaders can be both only an individual or in a group. Community leadership provides a general interpretation, referring to all community-development activities. In this context, leaders empower their community members to implement development activities through using sources and capacity, creativity, and innate potential. This is an organic process that covers dialogue and interaction, collective decision-making to set positive, confident, spirited, and result-oriented attitudes. For developed and developing countries, the leadership approach has shifted from authoritarian practices and individualistic authority control (especially driven by problem-based approach) to leaders that directly participate with community members, interdependent, positive, and caring (Rankin \& Engelbrecht, 2014). Leaders that participate with community members with positivity and affection that motivate and drive community members to transform and change the organisation or community collectively. Community leadership emphasises on relationships with community members, is positive, transforms creative potential to positive energy and builds confidence, energy, spirit, and performance. Relationship and trust are key elements in community leadership. This also includes qualities such as inspiration, vision, humility, and flexibility (Cooperrider \& Whitney, 1999; Bel, Chan \& Nel, 2014). However, most studies on leadership focus on more formal, larger, and complex organisations such as the government, business, and military. Studies in leadership in the community context has been limited and research are more inclined to study personal and interpersonal skills and knowledge (Rost,1993).

\subsection{Social Capital}

Social capital is used in research as an analytical tool to explain how culture, beliefs, and cooperation between individuals are closely-linked to economic development and the overall community. Social capital as understood as beliefs, norms, and networks that enable collective action is carried out directly in entrepreneurship and economic development. Social capital is the basic determinant of economic development (Zlatan Delić, Hariz Šarić, Nedim Osmanović, 2017). Sustainable community development is dependent on the quality of relationship between community members. The improvement of existing relationships in a community is also known as social capital, and is one effort to drive and help in improving the level of social relationship in a society, and has a large impact on social well-being. There are three dimensions in the social relationship of a community: bonding, bridging, and networking. These three dimensions are included in the social capital concept placed at a different and inter-connected level with one another. These three dimensions have a resonance measured through strength of relationship.

Community relationship is measured based on the strength of social relationship between individual and groups. Elements such as mutual trust, reciprocity, collective identity, cooperation, and norms, strengthen social relationships that require nurturing, maintaining, and sharing by at least two individuals within a community. According to Putnam (1993) and Fukuyama (2002), these elements are social capital in a community that produces positive attitudes and improves individual and community competence. This is also one of the main capital components based on network and credibility structures, capable to achieve the community socio-economic development goals. An established social capital can increase the resource mobilisation of a community and improve the socio-economic development of a community.

A study by Narayan and Pritchett (1995) found that social capital has a significant link with family income. Sabitini (2005) found there are relationship influences on social capital such as strong family ties, peers, voluntary groups, and activity and political participation on the long-term economic well-being of an individual.

\subsection{Personal Psychology}

Moyle (2006) opines that an individual is considered psychologically-empowered when there emerge changes in the individual psychological construct such as self-efficacy, self-esteem, and proactivity. Self-efficacy is the belief in one's ability to manage and act to complete a task, and strong in the face of challenges (Bandura,1986). Individuals with high self-efficacy are able to transform challenges into opportunities that benefit them. Actions can be taken with knowledge, skills, and endurance to transform their lives. In the CBO context, self-competence encourages rural women to build their self-efficacy by learning new skills in organised activities. Their participation in CBOs highlights their belief in their abilities to succeed within a group.

Proactive attitude, according to Schwarzer (1999) are personality traits related to motivation and taking action. Proactive individuals focus on problem-solving, although the problems are caused by a hostile environment. Previous studies found this proactive attitude has a strong link with self-efficacy (Schwarzer, 1999). Self-esteem, according to Branden (1994), has a significant relationship with women's ability to achieve economic empowerment. A high level of self-confidence energises an individual to overcome challenges, regardless of the opinion of others. It also leads someone to be more confident and independent, thus achieving the economic empowerment of the self and the family. In line with the studies of Eyben, Kabeer, and Cornwall, (2008) women courageous enough to change their options are capable of empowering their economy (Arinola Agness Aguda Oluwoa, Adesoji Onib, 2017).

Although there are many factors that influence empowerment, previous studies show participation as the most studied factor. Zaimah Ramli (2010) highlights participation in PWPK associations are capable of improving their 
economic status and contributing to their children's education. The leadership factor is least studied in the context of economic empowerment.

\section{Research Methodology}

Quantitative approach through cross-sectional surveys are applied in this study. It also provides an explanation on relationship and influence of participation, leadership, social capital, and internal psychology with the economic empowerment of PWPK members in Malaysia by studying samples from a selected population. This design is also selected as collection of data is carried out once, not repeated at another time with the same respondents (Alreck and Settle, 2004). The study population consists of members actively participating in economic activities in PWPK in Malaysia. In Malaysia, there are 776 PWPK, with an active membership of 13,989 individuals. Based on the Cochran formula (1977), the required sample size needed for this study are 433 active PWPK members in additional economic activities. As this study uses homogenous sampling from the aspects of family background, education, gender, and occupation, sample selection follows the stratified sampling method based on zones generalisable to PWPK members across Malaysia. These zones are represented by Negeri Sembilan (south), Kelantan (east), Selangor (central), and Kedah (north).

Questionnaires are used as instruments to collect information distributed to respondents to answer the research objectives and questions. In addition, qualitative methods through structured interviews and round-table discussions are also used to support and validate quantitative findings. Five RISDA officers in the Development Unit are selected for interviews. 20 individuals, consisting of RISDA agents and PWPK chairpersons are selected as participants in the round-table discussions. The researcher also uses secondary sources such as documents, bulletins, newspaper clippings, and RISDA circulars for information on PWPK. The SPSS version 23 using the Pearson Product-Moment Correlation dan Multiple Regression analysis is applied to answer the research objective and hypothesis. Descriptive and inferential statistics are used to analysed the research data. Descriptive statistics aim to explain individual and group traits as the first step in data analysis.

\section{Research Analysis And Findings}

This study contains two objectives. Firstly, studying the link between factors from a sociological and psychological perspective and economic empowerment. Sociological perspectives consist of factors of leadership, participation, and social capital (bonding) that becomes characteristics of community-based organisation structures. Secondly, determining the factors that become the main predictors influencing economic empowerment. To analyse these relationships, the researcher uses the Pearson Correlation Product Moment and Multiple Regression analysis in SPSS to obtain findings.

i. Link between Sociological and Psychological Factors and Economic

Empowerment

The Pearson product-moment correlation analysis is used to study the significant relationship of variables of participation, leadership, social capital, and economic empowerment. The correlation analysis findings show a positive and strong relationship between internal psychology and empowerment with the economy $(\mathrm{r}=.688, \mathrm{p}<$ $.05)$, a strong and significant relationship with participation $(\mathrm{r}=.529, \mathrm{p}<0.5)$, and leadership $(\mathrm{r}=.525, \mathrm{p}<0.5)$. It also has a moderate and significant relationship between close ties and economic empowerment $(\mathrm{r}=.440, \mathrm{p}<$ 0.5). the findings show sociological factors covering participation, leadership, and social capital, and internal psychological factors have a significant relationship with the economic empowerment of PWPK members, and thus support previous studies (Moyle et al., 2006; Yasmine F. Nader 2008; Mayoux, 2006; Saidu, 2014; Bharathi, 2005). For instance, Moyle et. al. (2006) also highlights a positive relationship between participation and economic and personal empowerment of members of Self-Help Groups in North-West India. There is also a high and positive relationship between participation in micro-credit economic activities and the socio-economic situation in Cairo (Nader, 2008). Their capability in income, savings, and assets are obtainable through active participation, good community leadership, strong social capital, and stable internal psychology.

ii. Influence of participation, leadership, social capital, and psychology on economic empowerment

This analysis aims to study the extent of variables of participation, leadership, social capital (bonding), and internal psychology in influencing the economic empowerment of PWPK in Malaysia. The results of multiple regression analysis show 49 per cent of variance $(\mathrm{R} 2=49.0)$ of economic empowerment is explained by three variables: internal psychology, leadership, and participation. The findings show leadership, participation, and internal psychology are significant predictors to economic empowerment. Leadership at the value of $\beta=.111, p=$ $.012<0.05$, participation with the value of $\beta=.114, p=.014<0.05$, and internal psychology with the value of $\beta$ $=.542, \mathrm{p}=.000<0.05$. However, when comparing the three variables, the standardised coefficient $\beta$ value shows internal psychology is the main predictor to economic empowerment of PWPK members. The more active their involvement in CBO activities, the higher their internal psychological empowerment and more benefits are earned from the association. In this situation, active interaction between members accelerate this transformation. Members psychologically empowered are able to obtain more benefits through association activities. Moyle et al., (2006) opines an individual is considered psychologically-empowered through observable changes in their psychological constructs such as self-efficacy, self-esteem, and proactivity. 


\section{Discussion and Summary}

Women economic empowerment is very important for women development across the world. Almost oneseventh of the world's female population are unable to fully achieve their economic potential and well-being guarantee (Eyben \& Comwall, 2008). Empowering women economically provides them with more control over their options in line with sustainable development goals (SDG). Women, especially in rural areas, who are economically less-empowered, are inclined to participate in CBOs to obtain economic and social support. Lewa (2000) identifies women associations as medium to achieve shared goals. In economic activities, for example, women collectively participate to generate income to cover personal and family expenses (Lewa, 2000; Malombe, $2000 \&$ Karanja, 2013). Expanding from the issue of women economic empowerment, this research studies the relationship between sociological factors cover three dimensions: participation, leadership, and social capital, and personal psychology with economic empowerment among members of Women Smallholder Groups (PWPK) in Malaysia. Furthermore, this study also aims to determine the main predictor in influencing this relationship.

The findings show the sociological factor covering participation, leadership, and social capital, and internal psychological factors have a significant relationship with the economic empowerment of PWPK members, thus supporting previous studies (Moyle et al., 2006; Yasmine F. Nader 2008; Mayoux, 2006; Saidu, 2014; Bharathi, 2005). Internal psychology is the factor with the strongest relationship and main predictor influencing the economic empowerment of PWPK members. This is then followed by sociological factor of participation, leadership, and social capital. The results can be understood that income from economic-generating activities can be improved through self-efficacy, self-esteem, and proactivity. Belief in self-capability and endurance against challenges drive PWPK members to work harder to improve the economic empowerment of the self and family. The results of the internal psychological improvement drive community members to actively participate in $\mathrm{CBO}$ activities. Proactive PWPK members obtain more benefits. They can access information and resource, coping strategies, social support, positive attitude, and improved self-image. However, as a CBO, this does not mean internal psychology serves as the sole variable influencing economic empowerment of PWPK members. In fact, other factors complete and contribute to economic empowermne.t this includes the organisational structure characteristics in CBO.

The findings also show sociological factors serving as organisational structure characteristics such as participation, leadership, and social capital have significant and moderate relationships with economic empowerment. Comparing the three characterist8ics, participation is the factor with the most significant relationship, followed by leadership and social capital. The more active the PWPK members in economicgenerating activities, the higher their economic empowerment. Through participation, their capability is improved to identify problems, plan, and implement activities that could contribute to sustainable development (Geidam, 2012). A strong internal psychology drives someone to actively participate to ensure increase in economic empowerment through economic activity. Christens, Peterson, and Speer (2011) studies whether there exists bidirectional reciprocity between community participation and psychological empowerment.

In addition, leadership also plays an important role in moving association activities. Although this study shows leadership has a moderate relationship and influence with economic empowerment, its role cannot be side-lined. In the PWPK context, leadership is collective, consisting of the chairperson and committee members appointed for a certain period. The PWPK chairpersons are mostly experienced individuals in carrying out economic activities in their communities. Therefore, the Chairperson acts to empower community members through effective interactive and social support to ensure CBO becomes an effective medium to PWPK members to increase economic empowerment.

In this study, social capital in the context of relationship strength among association members have a significant and moderate relationship with economic empowerment. However, although with positive relationship, this study also produces findings that show social capital is not significant in influencing the economic empowerment of PWPK. These findings are not without basis, as although individuals have joined the PWPK, most are more comfortable carrying out economic activities individually instead of collectively to avoid interpersonal conflict. Social capital is more significant in activities related to community and spirituality, collectively moved within the PWPK.

In conclusion, in the CBO context such as PWPK, internal psychology is the main predictor in economic empowerment. This means success in increasing sources of income is influenced by individual psychological capability. Proactivity, high self-confidence, and refusal to be discouraged are key characteristics for individuals to advance and improve their economic empowerment. However, in CBOs economic empowerment are not merely dependent on internal psychological factors, but also supported by other factors such as active participation, leadership, and social capital. Other unstudied factors such as human capital should also be developed and obtained by PWPK members to ensure the carried out economic activities greatly impact the economic empowerment of the self and family.

\section{Acknowledgements}

I would like to thank the Ministry of Education Malaysia for their support and funding this research via Fundamental Research Grant Scheme (FRGS), Vot No. FRGS/1/2017/SS06/UTHM03/3. 


\section{References}

1. Abbott, J. (1995). Community participation and its relationship to community development. Community Development Journal, 30(2), 158-168.

2. Arinola Agness Aguda-Oluwoa, Adesoji Onib. 2017. Impact of self esteem and marital status on the desire to attain economic empowerment among women in South West, Nigeria. Sociology and Social Work Review, 1(1), 22-34

3. Asnarulkhadi Abu Samah. (2006). Participation and quality of life: A study on the people's empowerment in a Malay village community. Pertanika J. Soc.Sci \& Human, 14(1), 11-25

4. Asnarulkhadi Abu Samah.(2011).Pendayaupayaan komuniti ke arah pemupukan komuniti sivil berkualiti. In Pembangunan komuniti:membina keupayaan dan potensi masyarakat. Serdang: Universiti Putra Malaysia.

5. Bandura, A. (1986). Social foundations of thought and action. Upper Saddle River, NJ: Prentice Hall.

6. Bell,C, Chan, M; Nel, P. 2014. The impact of participative and directive leadership on organisationalculture: An organisational development perspective. Mediterranean Journal of Social Sciences. 5(23), 1970-1985

7. Bess, K. D., Perkins, D. D., Cooper, D. G., \& Jones, D. L. (2011). A Heuristic framework for understanding the role of participatory decision making in community-based non profit. Am J Community Psychology, 47, 236-252.

8. Bharathi,R.(2005). Assessment of self help groups promoted under NATP on empowerment of women in agriculture. master's thesis, University of Agricultural Sciences, Dharwad.

9. Branden, N. (1994). The six pillars of self-esteem. Bantam Books, Inc.

10. Chandrashekar and Lokesh 2009. Role of SHGs in socio-economic change of vulnerable poor. International. NGO Journal ,4 (4), 127-131

11. Christens, B. D, Peterson, N. A, \& Speer, P. W. (2011). Community participation and psychological empowerment: Testing reciprocal causality using a cross-lagged panel design and latent constructs. Health Education \& Behavior, 38(4), 339-47.

12. Cooperrider, D.L, \& Whitney, D. K(1999). Appreciative inquiry.Williston,VT: Berrett Koehler Communications

13. Cummings, F. H. (1997). Role of participation in evaluation and implementation of development project. The International Journal of Knowledge Transfer and Utilization, 10(1), 24-33

14. Eyben, R.; Kabeer, N. and Cornwall, A. (2008)Conceptualising Empowerment and the Implicationsfor Pro-Poor Growth, paper for the DAC PovertyNetwork, Brighton: IDS

15. Ferdoushi Ahmed, Chamhuri Siwar, \& Nor Aini Idris. (2011). Contribution of rural women to family income through participation in microcredit: An empirical analysis. American Journal of Applied Sciences, 8(3), 238-245

16. Fukuyama, F.(2002). Social Capital and Development:The Coming Agenda.The SAIS Review.

17. Geidam, A. A. (2012). Assessment of participation in afforestation programme and relationship to empowerment. International Journal of Academic Research in Business and Social Sciences, 2(8), 310315.

18. Hashemi S.M, S.D. Schuler, dan A. N. Riley. 1996. Rural credit programs and women empowerment in Bangladesh .World Developlment, 24 (4), 635- 653

19. Hung, K., Sirakaya-Turk, E.\& Ingaram, L. (2010).Testing the efficacy of an integrative model for community participation. Journal of Travel Research, 50(3), 276-288

20. Ismail, Maimunah (2001). Malaysian Women in rural development and entrepreneurship: from rural producers to urban entrepreneurs.Asean Academic Press, London.

21. Jakimow, T. (2007). The rationale of self-help in development interventions: A case study of a selfhelp group programme in Tamil Nadu. Journal of South Asian Development, 2(1), 107-124.

22. Jariah, M. \& Laily, P. (1995). Project oriented research: enhancing the economic contribution of poor rural women. A report submitted to Japan International Cooperation Agency (JICA).

23. Jariah, M., Laily, P., Mumtazah, O. \& Aini, S. (2003). Report on mechanization \& technological adoption: scaling up micro enterprises to small scale enterprises. Monograph Series on Social Science. Serdang: Penerbit Universiti Putra Malaysia.

24. Karanja, P (2013). Factors that influence entrepreneurial success among women groups: A Case study of Makuyu Division. Kenyatta University.M.A thesis

25. Lewa, R. (2000). Law and the quest for gender equality in Kenya. English Press limited, Enterprises Road, Nairobi.

26. Mayoux, L. (2006). Women's empowerment through sustainable micro finance: rethinking "best practice." Retrieved from www.genfinance.net 
27. Mok, B. H. (2005). Organizing self-help groups for empowerment and social change. Journal of Community Practice, 13(1), 37-41

28. Malombe, 2000. Malombe, J. (2000). Women groups. Nairobi, Kenya

29. Moyle, T. L., Dollard, M., \& Biswas, S. N. (2006). Personal and economic empowerment in rural Indian women: A self-help group approach. International Journal of Rural Management, 2(2), 245-266

30. Moser, C. O. N. (1989). Gender planning in the third world: Meeting practical and strategic gender needs. World Development, 17(11), 1799-1825

31. Narayan, D. \& Pritchett. L. (1996).Cents and Sociability: Household Income and Social Capital in Rural Tanzania. Policy Research Working Paper 1796, Washington, DC: The World Bank

32. Ndaeji, M. N., \& Asnarulkhadi Abu Samah. (2013). Relationship between participation and empowerment in women self help group in Nigeria-A general analysis. World Rural Observation, 5(3), 3-7

33. Nur Hafizah Yusof, \& Rahimah Abdul Aziz. (2012). Pemerkasaan wanita desa : Kajian ke atas kumpulan ekonomi kuala Teriang, Langkawi, Kedah. Malaysia Journal of $\quad$ Society and Space, 6(6), 15-23

34. Opare, S. (2007). Strengthening community-based organizations for the challenges of rural development. Community Development Journal, 42(2), 251-264

35. Putnam, R. (1993).The Prosperous Community-Social Capital and Public Life. American Prospect, 4(13), $35-42$

36. Rankin, P. \& Engelbrecht, L.K. 2014. The context of management in social service organisations. In: Engelbrecht, L.K (ed) Management and supervision of social workers: Issues and challenges within a social development paradigm. Andover: Cengage Learning EMEA Limited.

37. Rekha Yadav, M.P. Sagar, Hema Tripathi, Parveen Kumar, B.L Balaraju, Sushil Sinha and Nukala Ramesh. 2016. Study of performance of women based Groups at individual level in Revari District of Haryana. Haryana Vet, 55(2), 206-209

38. Sabatini, F.(2005). Social capital as social networks. A New framework for measurement. The Journal of Socio-Economics, 38 (2009) 429-442

39. Saidu, M. B. (2014). Relationship between socio-economic factors and participation in decision making in microfinance scheme among rural farmers in Kano,Nigeria. Life Science Journal, 11(4), 342 347

40. Saidu, M., Asnarulkhadi, Ma'arof, \& Nobaya. (2014). Participation as a medium for economic empowerment among microfinance scheme beneficiaries in Kano, Nigeria. World Applied Sciences Journal, 31(4), 667-671

41. Schwarzer, R. (1999). Proactive attitude scale. Retrieved from http://userpage.fu-berlin.de/

42. Taylor\&Pereznieto. 2014.A Review of approaches and methods to measure economic empowerment of women and girl. Gender \& Development, 22(2), 235- 251

43. Yadav, R, Sagar, M.P, Tripathi,H, Kumar, P, Balaraju, B.L, Sinha, S.K \& Ramesh,N. $\quad 2016 . \quad$ Study of performance of women based self help groups at individual level in Rewari District of Haryana. Haryana Vet. 55 (2), 206-209

44. Yasmine F. Nader. (2008). Microcredit and the socio-economic wellbeing of women and their families in Cairo. The Journal of Socio-Economics, 37(2), 644-656

45. Zaimah Ramli. (2010). Pengurusan kredit mikro di kalangan wanita. Journal of Social Sciences and Humanities, 5(1), 132-141

46. Zlatan Delić, Hariz Šarić, Nedim Osmanović. 2017. Significance of social capital in socioeconomic development of Bosnia and Herzegovina. International Business Research,10(30),169182 